\title{
Pencegahan dan Tata Laksana Awal Penyakit Anemia pada Ibu Hamil di RSIA St. Khadijah 1 Makassar
}

\author{
Irna Diyana Kartika ${ }^{*}$, Asrini Savitri², Sri Wahyuni Gayatri ${ }^{3}$ \\ ${ }^{1}$ Departemen Patologi Klinik, Fakultas Kedokteran, Universitas Muslim Indonesia \\ ${ }^{2}$ Departemen Gizi Klinik, Fakultas Kedokteran, Universitas Muslim Indonesia \\ ${ }^{3}$ Departemen Biokimia, Fakultas Kedokteran, Universitas Muslim Indonesia \\ *Email korespondensi: irnadiyana@gmail.com \\ Telp: +6281342641642
}

\begin{abstract}
ABSTRAK
Anemia dalam kehamilan adalah kondisi ibu dengan kadar hemoglobin dibawah 11 gr\% pada trimester I dan III atau kadar <10,5 gr\% pada trimester II. Penyebab anemia pada umumnya adalah sebagai berikut: Kurang gizi (malnutrisi), kurang zat besi dalam diet, malabsorpsi, kehilangan darah banyak seperti persalinan yang lalu, haid dan lain-lain serta penyakit-penyakit kronik seperti TBC paru, cacing usus, malaria dan lain-lain. Kegiatan pengabdian ini dilaksanakan oleh 3 dosen dengan jumlah peserta 50 orang di Poliklinik RSIA Siti Khadijah 1. Dalam mencapai tujuan kegiatan digunakan metode pendampingan dan aplikasi mandiri bekerjasama dengan perawat serta analis laboratorium. Kegiatan dilakukan selama 2 hari. Pada hari pertama diikuti oleh 26 orang Ibu Hamil dan hari kedua diikuti oleh 24 orang ibu hamil. Kegiatan dilakukan dengan memberikan materi Penyuluhan Anemia pada ibu hamil kemudian melakukan screening pemeriksaan $\mathrm{Hb}$. Didapatkan sebanyak 43 orang ibu hamil pada trimester III mengalami anemia dan sisanya 5 orang trimester II juga mengalami anemia dan 2 orang trimester III normal. Setelah didapatkan jumlah ibu hamil yang mengalami anemia, maka kami segera memberikan edukasi dan tablet Fe agar dikonsumsi selama kehamilan dan rutin berkunjung ke dokter kandungan untuk Antenatal care. Dari hasil penyuluhan ditemukan bahwa $86 \%$ ibu hamil trimester III tidak mengetahui perlunya memeriksakan kadar hemoglobin sehingga mereka tidak memperhatikan asupan zat besi yang mereka konsumsi.
\end{abstract}

Kata kunci: Anemia; hemoglobin; ibu hamil

\begin{abstract}
Anemia in pregnancy is a condition of the mother with hemoglobin levels below 11 gr\% in trimesters I and III or levels $<10.5 \mathrm{gr} \%$ in trimester II. The causes of anemia in general are as follows: Malnutrition, lack of iron in the diet, malabsorption, heavy blood loss such as past labor, menstruation and others as well as chronic diseases such as pulmonary tuberculosis, intestinal worms, malaria and others -other. This service was carried out by 3 lecturers with 50 participants in the SIA Khadijah RSIA Polyclinic 1. In achieving the objectives of the activity, assistance and independent application methods were used in collaboration with nurses and laboratory analysts. Activities carried out for 2 days. The first day was attended by 26 pregnant women and the second day followed by 24 pregnant women. The activity was carried out by giving Anemia Counseling material to pregnant women then screening for $\mathrm{Hb}$ examination. Obtained as many as 43 pregnant women in trimester III have anemia and the remaining 5 trimester II people also have anemia and 2 trimester III people are normal. After getting the number of pregnant women who have anemia, we immediately provide education and Fe tablets to be consumed during pregnancy and regularly visit obstetricians for Antenatal care. From the results of counseling found that almost $86 \%$ pregnant women in third semester did not know the need to check their hemoglobin levels so they did not to pay attention to the iron intake they consumed.
\end{abstract}

Keywords: Anemia; hemoglobin; pregnancy 


\section{PENDAHULUAN}

Anemia pada kehamilan merupakan salah satu masalah nasional karena mencerminkan nilai kesejahteraan sosial ekonomi masyarakat dan pengaruhnya sangat besar terhadap kualitas sumber daya manusia. Anemia pada ibu hamil disebut "potensial danger to mother and child" (potensial membahayakan ibu dan anak). Oleh karena itulah anemia memerlukan perhatian serius dari semua pihak yang terkait dalam pelayanan kesehatan. Data World Health Organization (WHO) 2010, 40\% kematian ibu dinegara berkembang berkaitan dengan anemia dalam kehamilan. Kebanyakan anemia dalam kehamilan di sebabkan oleh defisiensi besi dan pendarahan akut, bahkan jarak keduanya saling berinteraksi. Anemia dalam kehamilan merupakan masalah kesehatan yang utama di negara berkembang dengan tingkat morbiditas tinggi pada ibu hamil. Rata-rata kehamilan yang disebabkan karena anemia di Asia diperkirakan sebesar $72,6 \%$. Tingginya pravalensinya anemia pada ibu hamil merupakan masalah yang tengah dihadapi pemerintah Indonesia.(1,2)

Data survei demografi dan kesehatan Indonesia (SDKI) pada tahun 2010 menyebutkan bahwa angka kematian ibu (AKI) di Indonesia sebesar 220 per 100.000 kelahiran hidup. Angka tersebut masih jauh dari target Rancangan Pembangunan Jangka Menengah (RPJMN) tahun 2014 sebesar 2118 per 100.000 kelahiran hidup dan target Milenium Develpomen Goals (MDG's) sebesar 102 per 100.000 kelahiran hidup tahun 2015. Pravalensi anemia ibu hamil di Indonesia adalah $70 \%$ atau 7 dari 10 wanita hamil menderita anemia. Anemia defisiensi besi dijumpai pada ibu hamil 40\%. Angka kejadian anemia kehamilan di Surakarta pada tahun 2009 adalah 9,39\%. Tercatat bahwa dari $11.441 \mathrm{ibu}$ hamil terdapat $1.074 \mathrm{ibu}$ hamil yang mengalami anemia kehamilan. Indonesia merupakan salah satu negara dengan jumlah penderita anemia kehamilan terbanyak. Program pemberian tablet Fe pada setiap ibu hamil yang berkunjung ke pelayanan kesehatan nyatanya masih belum mampu menurunkan jumlah penderita anemia kehamilan secara signifikan. Ketidakberhasilan program ini dipengaruhi oleh beberapa faktor diantaranya cara mengkonsumsi tablet Fe yang sesuai, baik dari segi waktu maupun cara mengkonsumsinya.(2-5)

Suatu penelitian memperlihatkan perubahan konsentrasi $\mathrm{Hb}$ sesuai dengan bertambahnya usia kehamilan. Pada trimester I, konsentrasi Hb tampak menurun, kecuali pada perempuan yang telah memiliki kadar $\mathrm{Hb} 3$ rendah $(<11,5 \mathrm{~g} / \mathrm{dl})$. Konsentrasi Hb paling rendah didapatkan pada trimester II, yaitu pada usia kehamilan 30 minggu. Pada trimester III terjadi sedikit peningkatan $\mathrm{Hb}$, kecuali pada perempuan yang sudah mempunyai kadar $\mathrm{Hb}$ yang tinggi (> 14,5 $\mathrm{g} / \mathrm{dl})$ pada pemeriksaan pertama. $(1,4,6)$ 
Anemia defisiensi besi merupakan anemia yang terbanyak baik di Negara maju maupun Negara yang sedang berkembang. Padahal besi merupakan suatu unsur terbanyak pada lapisan kulit bumi, akan tetapi defisiensi besi merupakan penyebab anemia yang tersering. Hal ini disebabkan tubuh manusia mempunyai kemampuan terbatas untuk menyerap besi dan sering kali tubuh mengalami kehilangan besi yang berlebihan yang diakibatkan pendarahan. Departemen Kesehatan RI memberikan standar pelayanan pemeriksaan ANC selama hamil sedikitnya 4 x pelayanan antenatal yaitu satu kali untuk trimester I, satu kali untuk trimester II, dan dua kali untuk trimester III, pemeriksaan meliputi anamnesa dan pemantauan ibu dan janin dengan seksama untuk menilai apakah perkembangan berlangsung normal. Bidan juga harus mengenal kehamilan resiko tinggi khususnya anemia kurang gizi, hipertensi. Bidan juga memberikan nasehat dan penyuluhan kesehatan serta tugas terkait lainnya. Dalam setiap kunjungan ANC bidan menonjolkan kepada ibu hamil apakah persediaannya cukup. Ikatan Bidan Indonesia (2000) untuk mendeteksi anemia pada kehamilan dilakukan pemeriksaan kadar $\mathrm{Hb}$ ibu hamil. Pemeriksaan dilakukan pertama sebelum minggu ke 12 dalam kehamilan dan minggu ke 28. Bila 4 kadar Hb kurang dari 11gr\% pada kehamilan dinyatakan anemia dan harus diberi suplemen tablet zat besi $(\mathrm{Fe})$ secara teratur 1 tablet/hari selama 90 hari. (7-10)

\section{METODE PELAKSANAAN}

\subsection{Tujuan Kegiatan}

Mengurangi angka kejadian anemia pada ibu hamil trimester III di RSIA Siti Khadijah 1 Makassar sehingga dapat mengurangi angka kematian pada ibu dan anak akibat anemia

\subsection{Lokasi Kegiatan}

Poliklinik Kandungan RSIA Siti Khadijah 1 Makassar, Sulawesi Selatan

\subsection{Metode Keegiatan}

Kegiatan pengabdian ini dilaksanakan oleh 3 dosen dengan cara pengambilan sampel secara total sampling dimana jumlah peserta 50 orang di Poliklinik RSIA Siti Khadijah 1. Dalam mencapai tujuan kegiatan digunakan metode pendampingan dan aplikasi mandiri bekerjasama dengan perawat serta analis laboratorium.

\subsection{Pelaksanaan Kegiatan}

Kegiatan pelaksanaan pengabdian kami laksanakan di RSIA Siti Khadijah 1 Makassar pada tanggal 01-02 Januari 2019 pukul 09.00 sampai 15.00 WITA. 
Tabel 1. Jadwal Pelaksanaan Kegiatan

\begin{tabular}{|c|c|c|}
\hline \multicolumn{3}{|r|}{ Tgl 1 Januari - 2 Januari 2019} \\
\hline No & Waktu & Kegiatan \\
\hline 1. & $09.00-09.30$ & $\begin{array}{l}\text { Penyuluhan tentang anemia dalam kehamilan dan penting konsumsi } \\
\text { tablet Fe }\end{array}$ \\
\hline 2. & $09.30-10.00$ & Tanya jawab dengan peserta \\
\hline 3. & $10.00-10.15$ & Pemberian bingkisan kepada peserta penyuluhan \\
\hline 4. & $10.15-15.00$ & $\begin{array}{l}\text { a. Pengambilan sampel darah untuk melakukan screaning } \\
\text { kadar } \mathrm{Hb} \\
\text { b. Edukasi pada ibu hamil yang memiliki kadar } \mathrm{Hb} \text { rendah atau } \\
\text { anemia } \\
\text { c. Pemberian zat besi (tablet } \mathrm{Fe} \text { ) dan bingkisan kepada ibu } \\
\text { hamil yang bersedia di periksa kadar Hbnya. }\end{array}$ \\
\hline 5 & $15.00-15.30$ & $\begin{array}{l}\text { Pemerian Banner dengan judul Anemia dalam kehamilan kepada } \\
\text { pihak RSIA Sitti Khadijah } 1 \text { Makassar }\end{array}$ \\
\hline
\end{tabular}

\section{HASIL DAN PEMBAHASAN}

Kegiatan pelaksanaan pengabdian kami laksanakan di RSIA Siti Khadijah 1 Makassar pada tanggal 01-02 Januari 2019 pukul 09.00 sampai 15.00 WITA. Kegiatan ini dihadiri oleh 50 orang ibu hamil mulai dari umur kehamilan trimester II dan III.

Kegiatan ini dilakukan dengan memberikan materi mengenai Anemia dalam kehamilan serta pentingnya konsumsi tablet Fe. Ibu-ibu hamil sangat antusias mendengarkan materi yang kami berikan dengan langsung mengadakan dialog tanya jawab mengenai materi yang kami berikan.

Kegiatan kedua yang kami berikan yaitu melakukan screening kadar hemoglobin darah pada ibu hamil. Dimulai dengan inform concent tentang tindakan yang akan dilakukan kemudian dilanjutkan dengan pengambilan darah vena pada jari ibu. Hasil yang diperoleh dari pemeriksaan tersebut didapatkan sebanyak 43 orang ibu hamil pada trimester III mengalami anemia dan sisanya 5 orang trimester II juga mengalami anemia dan 2 orang trimester III normal . Setelah didapatkan jumlah ibu hamil yang mengalami anemia, maka kegiatan ketiga kami yaitu segera memberikan edukasi kepada ibu hamil yang mengalami anemia dan pemberian tablet Fe agar dikonsumsi selama kehamilan dan rutin berkunjung ke dokter kandungan untuk ANC (Antenatal care). 
Setelah selesai pemberian materi, melakukan skiring kadar hemoglobin ibu, dari hasil skrining ibu yang anemia kami berikan tablet Fe, booklet dan bingkisan yang berisi makanan sehat dan susu khusus ibu hamil kepada peserta. Kemudian untuk RSIA Siti Khadijah kami berikan banner yang berjudul Anemia dalam kehamilan.

\section{KESIMPULAN DAN SARAN}

Dari hasil penyuluhan dan pemeriksaan ibu hamil di poliklinik RSIA Sitti Khadijah 1 Makassar di temukan kurangnya edukasi bagi ibu hamil tentang bahaya anemia saat hamil dan akibat kurangnya konsumsi kadar zat Fe (tablet Fe) saat hamil. Adapun saran kami hendaknya penyuluhan-penyuluhan tentang kesehatan pada umumnya dan ibu hamil pada khususnya rutin di lakukan di fasilitas kesehatan di kota Makassar.

\section{Ucapan Terima Kasih}

Dekan Fakultas Kedokteran UMI, Ketua LPMD-UMI yang telah memberikan bantuan dana kepada kami, Direktur RSIA Siti Khadijah 1 yang telah memberikan ijin kepada kami untuk melakukan pengabdian, semua pihak yang tidak dapat kami sebutkan satu persatu namanya yang telah memungkinkan selesainya pengabdian ini.

\section{DAFTAR PUSTAKA}

1. Bakta IM. Buku ajar ilmu penyakit dalam. In: VI. jakarta Pusat: Interna Publishing; p. 2015.

2. Chandranita IA. Obstetri \& ginekologi sosial untuk profesi bidan. In Jakarta: EGC; 2009.

3. $\quad$ RI KK. Riset kesehatan dasar 2010. In Jakarta: Bakti Husada; 2010.

4. Sarifuddin AB, Rachimhadhi T, Wiknjosastro GH. Ilmu kebidanan Sarwono Prawirdjo. In: 4th ed. Jakarta: PT Bina Pustaka Sarwono Prawirohardjo; 2016.

5. RI D. Penyakit Penyebab Kematian Bayi Baru Lahir (Neonatal) dan Sistem Pelayanan Kesehatan yang Berkaitan di Indonesia. In Jakarta: Depkes RI; 2002.

6. Setywan H, Nurhayati, CA A, Endang. Pengaruh Anemia Ibu Hamil Trisemester III Terhadap Kejadian Bayi Berat Lahir Rendah (BBLR), Prematuritas dan Intra Uterine Growth Retardation (IUGR). J Epidemiol Indones. 2009;1(3):9-15.

7. Rizki F, Lipoeto NI, Ali H. Hubungan Suplementasi Tablet Fe dengan Kadar Hemoglobin pada Ibu Hamil Trimester III di Puskesmas Air Dingin Kota Padang. J Kesehat Andalas. 2017;6(3):502-6.

8. Hanifa Wiknjosarto D. Ilmu kebidanan. In: 4th ed. Jakarta: Yayasan Bina Pustaka Sarwono Prawirohardjo; 2009.

9. Cuningham G. Obstetri Williams. In: 23, Volume ed. Jakarta: EGC; 2017.

10. Saifuddin AB. Buku acuan nasional pelayanan kesehatan maternal dan neonatal. In Jakarta: Yayasan Bina Pustaka Sarwono Prawirohardjo; 2009. 